\title{
DEVELOPMENT OF CHILDREN'S COGNITIVE ABILITIES THROUGH INTERACTIVE APPLICATIONS
}

\author{
Filip Mauzner, Lidija Mandić (iD), Ana Agić (iD), Jesenka Pibernik (iD) \\ University of Zagreb, Faculty of Graphic Arts, Zagreb, Croatia
}

\begin{abstract}
In this paper we present the development of cognitive abilities in kindergarten children with interactive applications. Practical part includes the design of application prototype used for the development of cognitive abilities in children age three to four. It comprises three categories in which children's cognitive abilities are tested and being developed. The categories are colors, numbers, shapes and sizes.
\end{abstract}

Key words: application, cognitive abbilities, color, numbers, shapes

\section{INTRODUCTION}

Today, children, no matter where they live, will have to face the phenomenon of change. To prepare children, in order to be ready to become persons who will reach new knowledge, it is necessary to develop the basics for learning skills that are key factors in meeting modern challenges.

In principle, in the field of early childhood education and development, there are two basic approaches to the study of children aged three to six (Hansen et al, 2006). The first is the behaviorist approach, which implies that the concepts of learning do not originate from the child himself and do not develop spontaneously. An approach that is fundamentally opposite to the behaviorist one is called a developmental approach. Two lines of development - natural and social - continuously interact with the development of the child's thinking. Cognitive development is initially the result of direct experience from the environment, but as they develop, children become able to transform their own experience through thinking. The pace of individual development depends on the social environment. Cognitive development involves large, qualitative changes in thinking. Piaget believed that children go through different stages as they grow up. The first is sensory motor, which occurs after birth and lasts until the second year (Duran, 1995). The second lasts from the second to the eleventh year and represents the degree of concrete action. The third occurs in early adolescence through the degree of formal actions. Vygotsky changes his mind about when children become able to communicate with the help of speech and when they are instructed to become aware of their own thoughts and master them. Erickson's theory speculates on three phases related to childhood that reflect an individual's relationship to the social environment. Healthy development is the resolution of conflicts typical of a certain age. From birth to the third year, the child develops trust, from the first to the third year the child develops his autonomy, and from the third to the sixth year the individual acquires a sense of initiative.

The Step by Step program is a unique program for children aged three to six and their families (Slunjski et al, 2014). The educational plan and program is such that it combines research practice in early childhood education and strong connections and work with families, in order to individualize the experiences of each child. The program is designed to meet the unique needs of each child, while taking into an account the diversity of cultures and traditions. The program is characterized by an emphasis on 3 basic principles: individualization, independent choice of activities and partnership with parents and other family members. The philosophy of the program is based on the belief that children develop best when they are truly involved in their own learning. Important features that the "Step by Step" program encourages in children are the ability to adequately cope with influence change, to make critical judgments and choices and to detect and solve problems

\section{THE INFLUENCE OF INTERACTIVE MEDIA ON CHILDREN`S DEVELOPMENT}

With so many variations of types games, it is difficult to guess whether the games are generally good or bad. Numerous studies have been conducted on this topic and information on the advantages and disadvantages they can be easily found. Studies have shown a negative impact video games for younger generations. Kids who spend more time playing violent games had faster heartbeats, more often reported dizziness and nausea and showed more aggressive thoughts in a later test than children who played 
nonviolently games (Shapiro, 2014). Another reason for the negative impact of games on children is the impact on their social life. Children prefer to play on a console or mobile phone instead of playing outdoors, on a playground, etc. Children are less likely to enroll in extracurricular activities which prevents them from meeting new people and making new friendships. Positive aspects of games have shown that playing video games can be useful for the development of many cognitive functions and can also be socially beneficial (Venderbilt, 2014). Players can learn strategy and expectations, resource management, recognition samples, quantitative calculations, etc. Players also get used to multitasking (performing multiple actions simultaneously) through tasks that force them to simultaneously deal with multiple elements or ideas in the game. There are advantages: such as the development of hand-eye coordination, fine motor skills and a sense of space. Games also contain social component, stimulate communication and the learning experience. They are often already familiar with downloading applications from service to the device and work with them. Most kids love to download apps that have fun like games, stories, videos, etc. In case parents are the ones downloading apps for their kids, they mostly prefer applications that are educational and creative. These are applications that focus on the development of specific sets skill. Children respond positively to awards and compliments which are good for their self-esteem. Challenging and rewarding applications make a child happy while using the application and thus ensure that you continue to use them.

\section{EXPERIMENT}

In the experimental part, an application was designed and developed for development of cognitive abilities of kindergarten children. The target age group were children from three to four years. The application contains material suitable for more advanced children suitable for the age group of four to five years. After the development, the research was carried out in the kindergarten group in the "Jarun Kindergarten" Medo group. The educators were performed certain aspects of research and participate in the development of games for children. The children were accessed according to the "Step by Step" program. The role of the educator was to respond to the results of solving children's tasks and determine in which areas and why a particular child has problems if the application indicates so.

The name of the application itself is "Cogi". The application is a demo version. („High fidelity” prototype) in which the emphasis is primarily on the functional part of the game in order to test the impact on the development of children's cognitive abilities. The app in the current demo version requires additional engagement a person, who guides the child through play on occasion solving because there is no built-in voice element that would guide the children in solving the game and setting tasks. The advantage of this engagement is the possibility observations of the child's attitude, desire and success of solving tasks.

The tasks are made according to the map of the appropriate development of children from three to four years according to the international program for children's development "Step by step". Advanced tasks are added according to the map of appropriate development of children from four up to five years of age from the same program. The basic things that are in the application from the map of appropriate development are: numbers from 0 to 4, advanced level: up to 7; basic RGB colors and variations of them, advanced level: random added colors and basic shapes and size ratio, advanced level: some shapes added and combinations and size relationships (largest, smallest)

The application contains four menus. The first is a simple game in which they are chosen levels and tasks to be solved. The first menu shows 5 active categories that children can solve. These five categories are gestures, colors, numbers, shapes and sizes and the last category is advanced that combines color numbers and shapes as it is shown in figure 1.

The second menu is the test menu the progress of each child can be monitored individually. The results can show how the child solves the game and progresses in individual categories. The number and result of individual games is visible, so it is from of this easily visible progress.

Next menu is results. The results can show how the child solves the game and progresses in individual categories. The number and result of individual games is visible, so it is from of this easily visible progress. The last menu is options and customizations for the app itself. The adjustments are simple and few: turn sound, voice, and animation on or off, or change of language. 


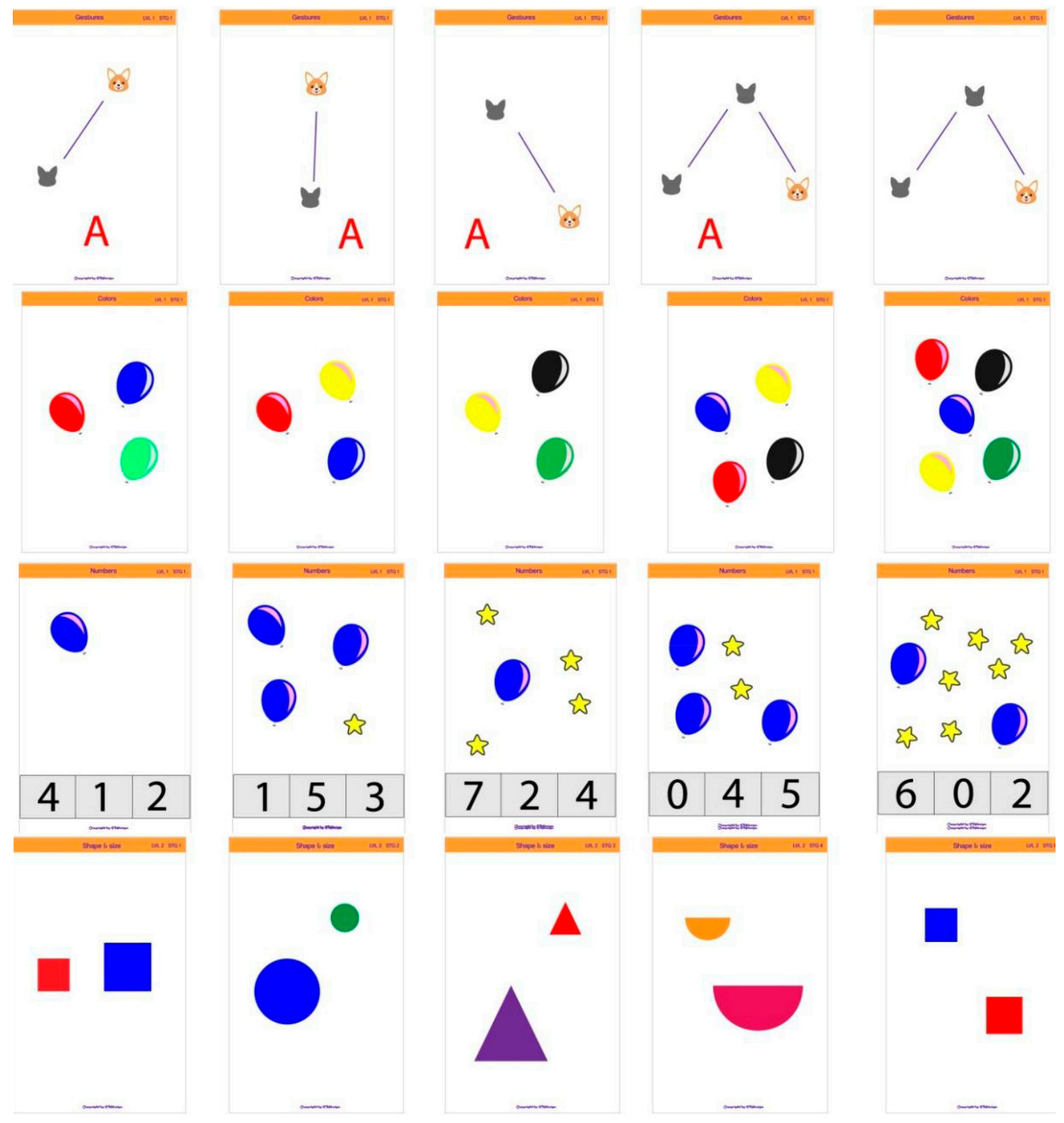

Figure 1: Categories: gestures, colors, numbers and size and shapes

The first category of the application is used to introduce the child to the gestures that operate on touch devices. Basic gestures include "touch", "swipe", drag and drop. The actions are straight, circular, with multiple elements at once to make the child already initially accustomed to different sides of the movement and the possibility of action on the screen. Tasks in which the elements are mixed colors encourage the child to conclude the correct response by elimination. First in tasks in which all the elements are in one color except the one that is the correct answer. Later, the number of multicolored elements increases and thus the number of colors with which a certain element is painted. In solving number tasks it is expected that children from three to four years of age recognize and count from 0 to 4 without major problems. The numbers are pretty represented in children's lives. Children like to count, look for two or three more sweets, etc. As the level increases, children are given tasks with numbers up to 7 and it is important expose the child to a problem where they need to recognize what needs to be counted or if needed count all the elements in the picture. In fourth category it is necessary to distinguish between shapes and sizes. The forms are square, circle, triangle and semicircle. The most important item in this category is that children are slowly getting used to the proper one shape names like squares (not cubes) and to learn the size ratio: larger, largest. Children in the age group of three to 
four recognize which element it is larger but if there are more than two comparable elements they have problems with descriptions larger and largest.

In order to motivate the child and inform him about the success of solving with everyone with the correct answer the message bravo appears with the smiling face of the dog breed corgi and shows the child that he answered correctly. In case of incorrect the answer appears a sad figure of a dog.

Twenty-seven children were tested.

\section{RESULTS}

Three tests were conducted for all categories to see children's progress. From first testing with color the results show that children recognized the colors according to their age. The category with the numbers shows more deviation from the success of solving tasks regardless of the age of the children. Children have no problem recognizing the basics shapes and call them by proper names and compare their sizes and relationships. The interesting thing about the second round of testing is that there are some children who are either rejected whole first testing or given up in the middle of testing ask for playing. In the third testing, 4 children who had difficulty solving tests were tested again in order to find whether they will be more successful after repetitions.

\section{CONCLUSION}

Today, technology has large impact on children. Games have positive and negative impact on children. By concentrating on the positive influence of games we could develop children's cognitive abilities. Creating an application and testing show positive results in learning. Technology is still an element that can complement cognitive abilities but not replace it. Children need physical contact with the world, learn through touch, smell and other senses. Also, if today's technology is used in a coercive way, performance is drastically reduced. The role of parents, educators, friends and enemies no one application can replace. The symbiosis of the real and virtual world could benefit today's children on a larger scale level than ever before in history but only if it is properly implemented.

\section{REFERENCES}

[1] Duran, M.: "Dijete i igra”, (Naklada Slap, Jastrebarsko, 1995.).

[2] Hansen, K., Kauffman, R., Walsh, K.: "Kurikulum za vrtiće, Razvojno primjereni program od 3 do 6 godina", (Pučko otvoreno učilište Korak po Korak, Zagreb, 2006.).

[3] Shapiro, URL: http://www.forbes.com/sites/jordanshapiro/2014/08/27/a-surprisingnew-study-on-howvideo-games-impact-children/ - A surprising new study how video games impact children, (last request: 2019-03-11.).

[4] Slunjski, E., Vujučić, L., Burić, H., Jaman-Čuveljak, K., Pavlic, K., Franko, A., Luetar, M.P., Guštin, D., Drviš, D.: "Nacionalni kurikulum za rani i predškolski odgoj i obrazovanje", (Ministarstvo znanosti, obrazovanja i sporta, Zagreb, 2014.).

[5] Venderbilt, URL: https://my.vanderbilt.edu/developmentalpsychologyblog/2014/04/effect -of-video-games-onchild-development/ - Effect of video games on child development, (last request: 2019-10-11.).

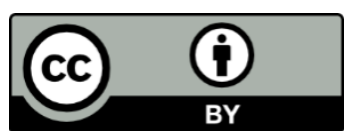

(C) 2020 Authors. Published by the University of Novi Sad, Faculty of Technical Sciences, Department of Graphic Engineering and Design. This article is an open access article distributed under the terms and conditions of the Creative Commons Attribution license 3.0 Serbia (http://creativecommons.org/licenses/by/3.0/rs/). 